\title{
Additive Manufacturing of Advanced High Temperature Masking Fixtures for EBPVD TBC Coating
}

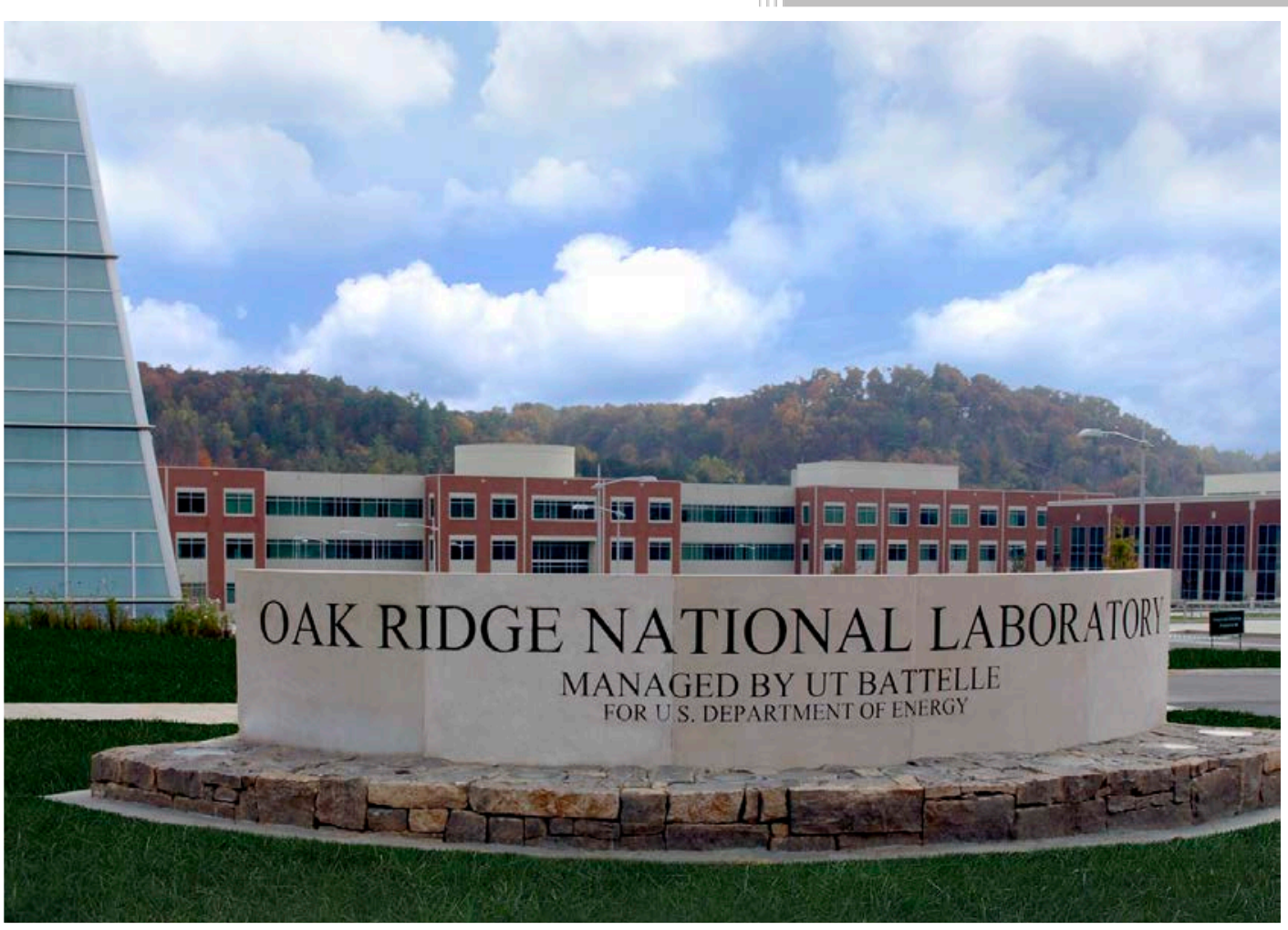

CRADA FINAL REPORT

NFE-14-05142

Approved for Public Release.

Distribution is Unlimited.
Ryan Dehoff

Fred List Michael Kirka Keith Carver Albert Feuerstein

March 30, 2016 


\section{DOCUMENT AVAILABILITY}

Reports produced after January 1, 1996, are generally available free via US Department of Energy (DOE) SciTech Connect.

Website http://www.osti.gov/scitech/

Reports produced before January 1, 1996, may be purchased by members of the public from the following source:

National Technical Information Service

5285 Port Royal Road

Springfield, VA 22161

Telephone 703-605-6000 (1-800-553-6847)

TDD 703-487-4639

Fax 703-605-6900

E-mail info@ntis.gov

Website http://www.ntis.gov/help/ordermethods.aspx

Reports are available to DOE employees, DOE contractors, Energy Technology Data Exchange representatives, and International Nuclear Information System representatives from the following source:

Office of Scientific and Technical Information

PO Box 62

Oak Ridge, TN 37831

Telephone 865-576-8401

Fax 865-576-5728

E-mail reports@osti.gov

Website http://www.osti.gov/contact.html

This report was prepared as an account of work sponsored by an agency of the United States Government. Neither the United States Government nor any agency thereof, nor any of their employees, makes any warranty, express or implied, or assumes any legal liability or responsibility for the accuracy, completeness, or usefulness of any information, apparatus, product, or process disclosed, or represents that its use would not infringe privately owned rights. Reference herein to any specific commercial product, process, or service by trade name, trademark, manufacturer, or otherwise, does not necessarily constitute or imply its endorsement, recommendation, or favoring by the United States Government or any agency thereof. The views and opinions of authors expressed herein do not necessarily state or reflect those of the United States Government or any agency thereof. 
ORNL/TM-2016/144

CRADA/NFE-14-05142

Materials Science and Technology Division Advanced Manufacturing Office

\title{
Additive Manufacturing of Advanced High Temperature Masking Fixtures for EBPVD TBC Coating
}

\author{
Authors \\ Ryan Dehoff \\ Fred List \\ Michael Kirka \\ Keith Carver \\ Albert Feuerstein (Praxair Surface Technologies, Inc.) \\ Date Published: \\ March 30, 2016 \\ Prepared by \\ OAK RIDGE NATIONAL LABORATORY \\ Oak Ridge, Tennessee 37831-6283 \\ managed by \\ UT-BATTELLE, LLC \\ for the \\ US DEPARTMENT OF ENERGY \\ under contract DE-AC05-00OR22725
}

Approved for Public Release 


\section{CONTENTS}

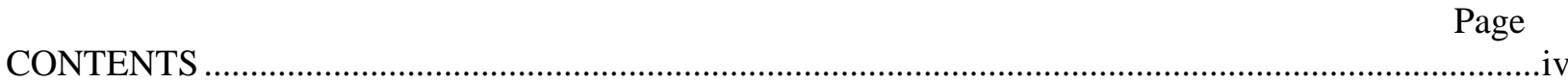

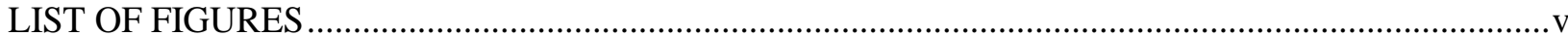

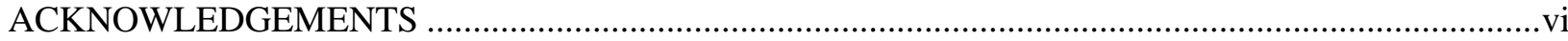

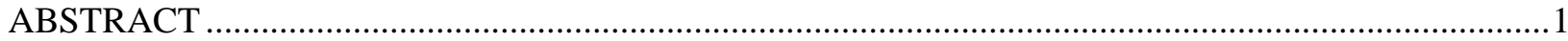

1. ADDITIVE MANUFACTURING OF ADVANCED HIGH TEMPERATURE MASKING

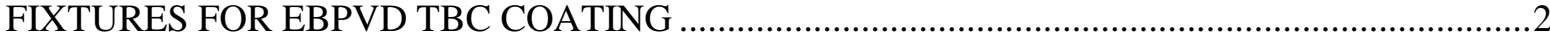

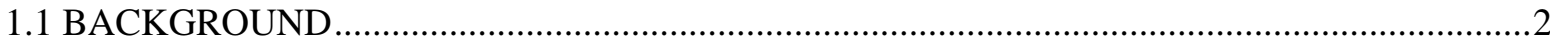

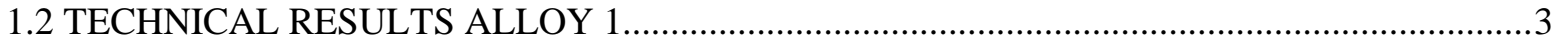

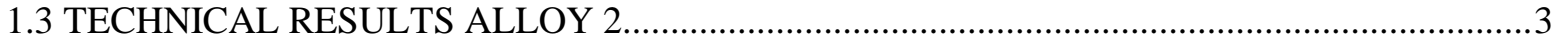

1.4 IMPACTS

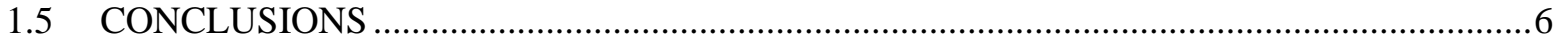

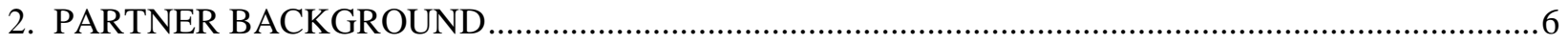




\section{LIST OF FIGURES}

Fig. 1. Representative build geometry of the fixture component. All proprietary design information has been removed..

Fig. 2. Image of 25 1-cm cubes of high temperature alloy 1 used to optimize LSM processing for high temperature alloy 1 . The blue circles indicate the cubes for which metallography was performed.....

Fig. 3. Metallographic cross-sections of high temperature alloy 1 showing a range of porosity microstructure.

Fig, 4. Custom structure developed to thermally and mechanically support the mask fixture during building. 


\section{ACKNOWLEDGEMENTS}

This CRADA NFE-14-05102 was conducted as a Technical Collaboration project within the Oak Ridge National Laboratory (ORNL) Manufacturing Demonstration Facility (MDF) sponsored by the US Department of Energy Advanced Manufacturing Office (CPS Agreement Number 24761).

Opportunities for MDF technical collaborations are listed in the announcement "Manufacturing Demonstration Facility Technology Collaborations for US Manufacturers in Advanced Manufacturing and Materials Technologies” posted at http://web.ornl.gov/sci/manufacturing/docs/FBO-ORNL-MDF-2013-2.pdf. The goal of technical collaborations is to engage industry partners to participate in short-term, collaborative projects within the Manufacturing Demonstration Facility (MDF) to assess applicability and of new energy efficient manufacturing technologies. Research sponsored by the U.S. Department of Energy, Office of Energy Efficiency and Renewable Energy, Advanced Manufacturing Office, under contract DE-AC0500OR22725 with UT-Battelle, LLC. 


\begin{abstract}
The purpose of this Manufacturing Demonstration Facility (MDF) technical collaboration project between Praxair Surface Technologies, Inc. (PST) and Oak Ridge National Laboratory (ORNL) was to develop an additive manufacturing process to fabricate next generation high temperature masking fixtures for coating of turbine airfoils with ceramic Thermal Barrier Coatings (TBC) by the Electron Beam Physical Vapor Deposition (EBPVD) process. Typical masking fixtures are sophisticated designs and require complex part manipulation in order to achieve the desired coating distribution. Fixtures are typically fabricated from high temperature nickel (Ni) based superalloys. The fixtures are fabricated from conventional processes by welding of thin sheet material into a complex geometry, to decrease the weight load for the manipulator and to reduce the thermal mass of the fixture. Recent attempts have been made in order to fabricate the fixtures through casting, but thin walled sections are difficult to cast and have high scrap rates.
\end{abstract}

This project focused on understanding the potential for fabricating high temperature Ni based superalloy fixtures through additive manufacturing. Two different deposition processes; electron beam melting (EBM) and laser powder bed fusion were evaluated to determine the ideal processing route of these materials. Two different high temperature materials were evaluated. The high temperature materials evaluated were Inconel 718 and another Ni base alloy, designated throughout the remainder of this document as Alloy X, as the alloy composition is sensitive. Inconel 718 is a more widely utilized material for additive manufacturing although it is not currently the material utilized for current fixtures. Alloy $\mathrm{X}$ is the alloy currently used for the fixtures, but is not a commercially available alloy for additive manufacturing. Praxair determined it was possible to build the fixture using laser powder bed technology from Inconel 718. ORNL fabricated the fixture geometry using the EBM technology in order to compare deposition features such as surface roughness, geometric accuracy, deposition rate, surface and subsurface porosity, and material quality. It was determined that the laser powder bed technology was ideal for the geometry and requirements of the fixture set by Praxair, and Praxair moved forward with the purchase of a laser powder bed system.

The subsequent portion of the project focused on determining the ideal processing parameters for alloy X for the laser powder bed system using ORNL's Renishaw laser powder bed system. Praxair supplied gas atomized powders of alloy X material with properties specified by ORNL. ORNL printed text cube arrays in order to determine the ideal combination of laser powder and laser travel speed in order to maximize material density, improve surface quality, and maintain geometric accuracy. Additional powder supplied by Praxair was used to fabricate a full-scale fixture component. 


\section{ADDITIVE MANUFACTURING OF ADVANCED HIGH TEMPERATURE MASKING FIXTURES FOR EBPVD TBC COATING}

This phase 1 technical collaboration project MDF-TC- 14-045 was begun on July 11, 2014 and was completed on June 30, 2015. The collaboration partner Praxair Surface Technologies is a large business.

\subsection{BACKGROUND}

Most modern aircraft engine gas turbine airfoils are currently coated with a ceramic thermal barrier coating using Electron Beam Physical Vapor Deposition (EBPVD). Praxair Surface Technologies (PST) operates worldwide four coating facilities dedicated to this technology. EBPVD of thermal barrier coatings is a vacuum process where substrates are exposed to a vapor cloud in a high vacuum environment at a temperature of approximately $2000 \mathrm{~F}$. Because the process is a line of sight process, the parts / fixtures need to be manipulated to achieve the desired coating distribution. Some surfaces of the parts/fixtures not requiring protection are masked to prevent coating deposition.

Because of the limited size of the vapor cloud, it is essential for productivity reasons to bring as many parts as possible into the vapor cloud. This requires sophisticated masking fixtures and complex part manipulation. Masking fixtures for the EBPVD process are currently fabricated from high temperature alloys such as high temperature alloy 2. Fixtures are typically welded from thin sheet metal to reduce the weight load for the manipulator and also to reduce the thermal mass of the fixtures to allow a rapid heat up to the desired process temperature approximately $2000^{\circ} \mathrm{F}$. After several coating runs the masking fixtures need to be stripped from coating, so there is a requirement for a smooth surface which can be easily cleaned by a waterjet or other stripping processes. The process is extremely sensitive to contaminants entrapped in the fixtures, so porosity and crevices (e.g. created by the welding process) are not allowed. Recently there have been made attempts to cast the fixtures to eliminate some of the above mentioned disadvantages of welded designs, but the casting process typically has issues with thin walled sections of the fixtures. Substantial effort is allocated to the mold design to reliably generate those thin walled sections.

Additive manufacturing (AM) does not have the limitations of welding and casting, and seems to provide unique benefits such as:

- Weight reduction by use of unique design features to reduce the wear in the part manipulation system

- Utilize designs which lead to reduced thermal mass such as to enhance the heat up rates to process temperature and thus gain productivity

- Utilize the unique design flexibility of AM to create complex space saving masking fixtures with increased packing density and thus improved productivity

- $\mathrm{AM}$ is a tool to develop new masking concepts in an extremely short time frame, which is essential in new product development.

Additive manufacturing has the potential to replace cast fixtures in the future. PST is already exploring additive manufacturing as a tool to produce rapid prototypes for cast fixtures to shorten their time to market and is already now seeing the time savings as a major benefit. In the future, PST envisions using AM technology for numerous end use applications. The masking fixture was chosen as a model to demonstrate some of the potential of the technology. As PST becomes more comfortable with AM technologies, the frequency of AM use will become more prevalent. 


\subsection{TECHNICAL RESULTS ALLOY 1}

Praxair worked with an industrial partner in order to fabricate a component using selective laser melting from Inconel 718. Process parameters for this material are commercially available for many of the laser powder bed systems, however many materials producers will perform subsequent modifications to the process parameters in order to improve mechanical properties and decrease the overall porosity content of the material. This was set as the baseline for what is commercially available through the current supply chain. A representation of the component is shown in Figure 1. The purpose of the work using electron beam melting was to determine if the component could be fabricated in less time using the Arcam electron beam melting process as this is required for production.
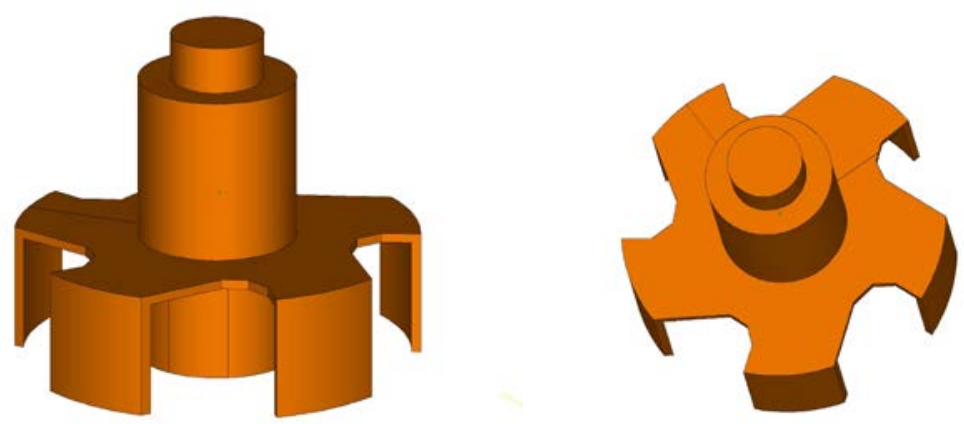

Fig. 1. Representative build geometry of the fixture component. All proprietary design information has been removed.

ORNL fabricated the component from Inconel 718 using the Arcam Electron Beam Melting (EBM) S12 technology with a modified vacuum insert for working with high temperature materials. The total build time for the component on this system was nearly identical to that of the laser powder bed process. However, the surface roughness of the component using the EBM was inferior to the surface finish of the laser-fabricated component. In addition, the support structure used in the EBM process was not easily removed. During the timeframe of the technical collaboration, Arcam released processing parameters for Inconel 718 for the A2X system. The A2X machine version was specifically designed to work with high temperature materials and therefore the processing parameters could be optimized for speed. A similar component (nearly identical wall thickness and area per layer) with z height of $300 \mathrm{~mm}$ tall was fabricated by Arcam in 50 hours using the A2X machine. The estimated build time for the component in figure 1 using the new version of software on the A2X machine would be under 25 hours. However, it was outside the scope of this work to fabricate a component using this system.

\subsection{TECHNICAL RESULTS ALLOY X}

Praxair determined that for this particular component, laser powder bed processing was superior to EBM due to faster deposition rate and better surface finish. Therefore, Praxair purchased a laser powder bed system in order to begin producing components. Although feasibility of AM production of this component was demonstrated, the actual in service component must be fabricated from Alloy X. To 
improve part quality, ORNL utilized the Renishaw laser powder bed system to run preliminary trials on Alloy X supplied by Praxair to determine the processing conditions necessary.

ORNL has previously demonstrated success depositing Inconel 718 for certain structures using the laser powder bed process. To extend this success to high temperature Alloy X, tests were first conducted with high temperature Inconel 718 powder processing parameters. Figure 2 shows an image of twenty-five 1-cm cubes of high temperature Alloy X that were prepared for various laser exposure times and speeds.

Figure 3 shows cross-sectional metallography for five of the cubes in Figure 2. Based on the observed defects, low exposure times (samples A1 and E1) lead to equiaxial porosity that suggests undermelting of the powder. By contrast, high exposure times (samples A5 and E5) result in elongated porosity where the long axis of the porosity is parallel to the build direction. This porosity is reminiscent of solidification cracking frequently observed when welding austenitic stainless steels.

Using knowledge derived from these initial tests, proprietary masking fixtures were successfully built with Inconel 718. The complexity of the fixtures required the development of custom support structures that are shown in Figure 4. Such structures provided thermal and mechanical support of the masking fixtures during building, and enabled removal of the fixtures from the build plate after the fixtures were complete. An exercise was scheduled and conducted at ORNL in which two employees were provided with hands-on instructions for removal of the masking fixture from the build plate, and a detailed list of process parameters used to build Inconel 718 fixtures.

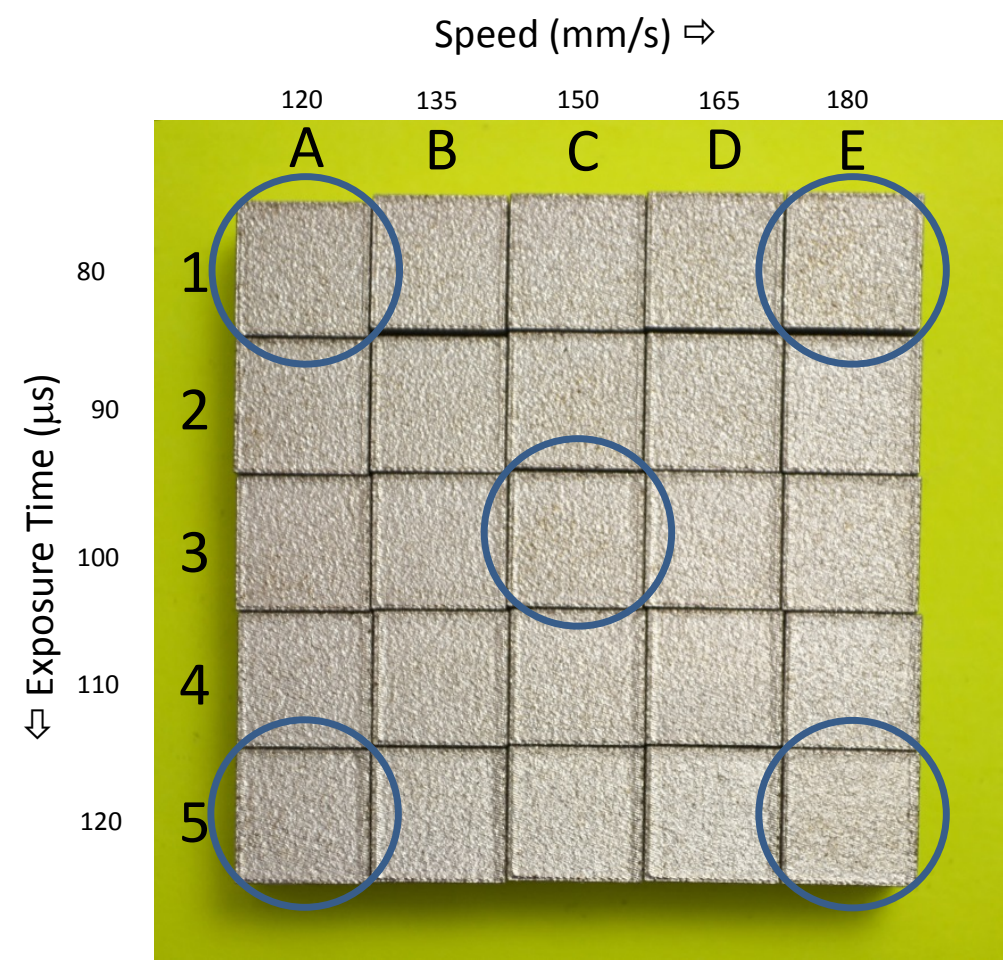

Fig. 2. Image of $251-\mathrm{cm}$ cubes used to optimize processing parameters Alloy $\mathrm{X}$. The blue circles indicate the cubes for which metallography was performed. 


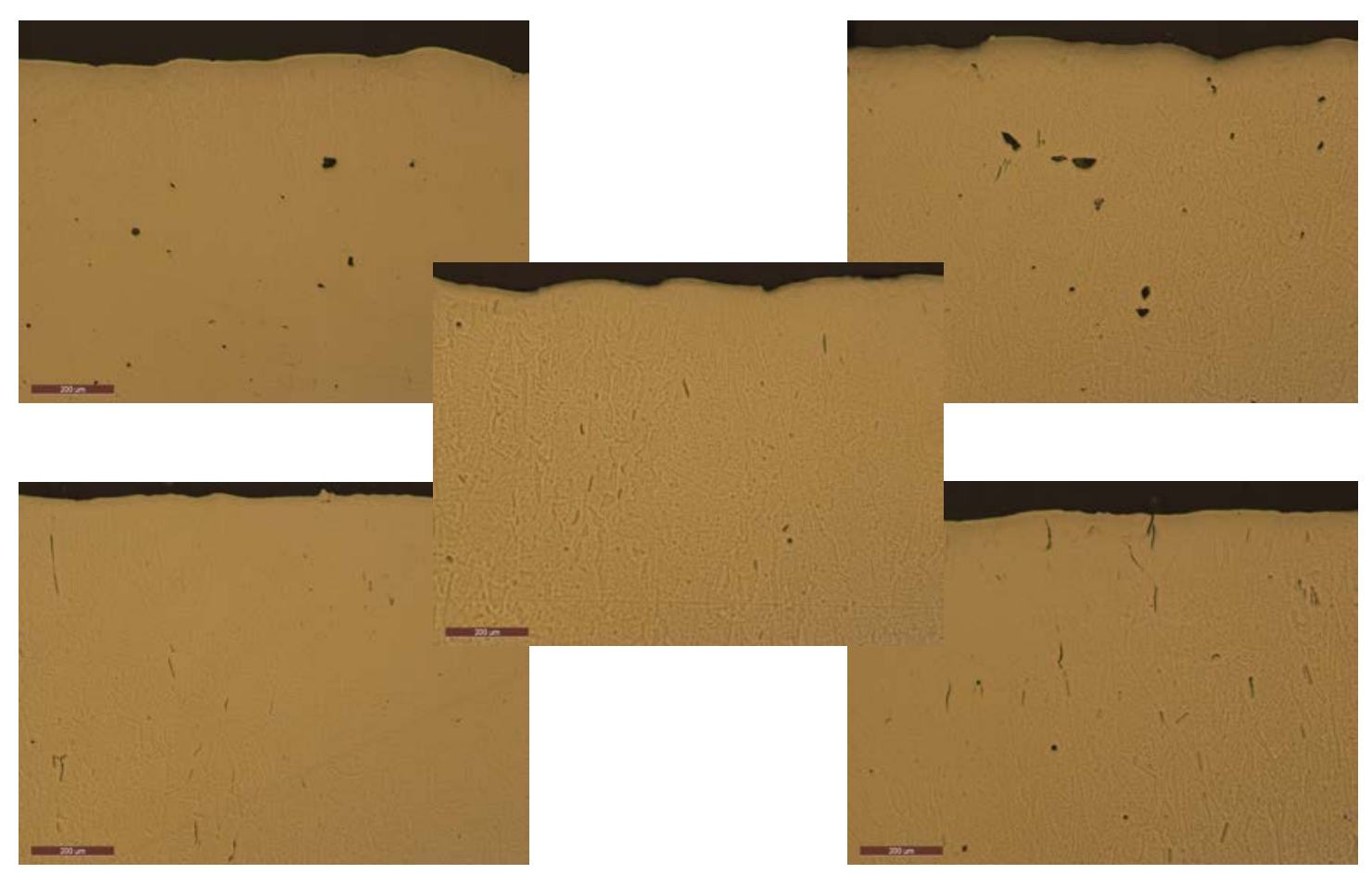

Fig. 3. Metallographic cross-sections of high temperature alloy 1 showing a range of porosity microstructure.

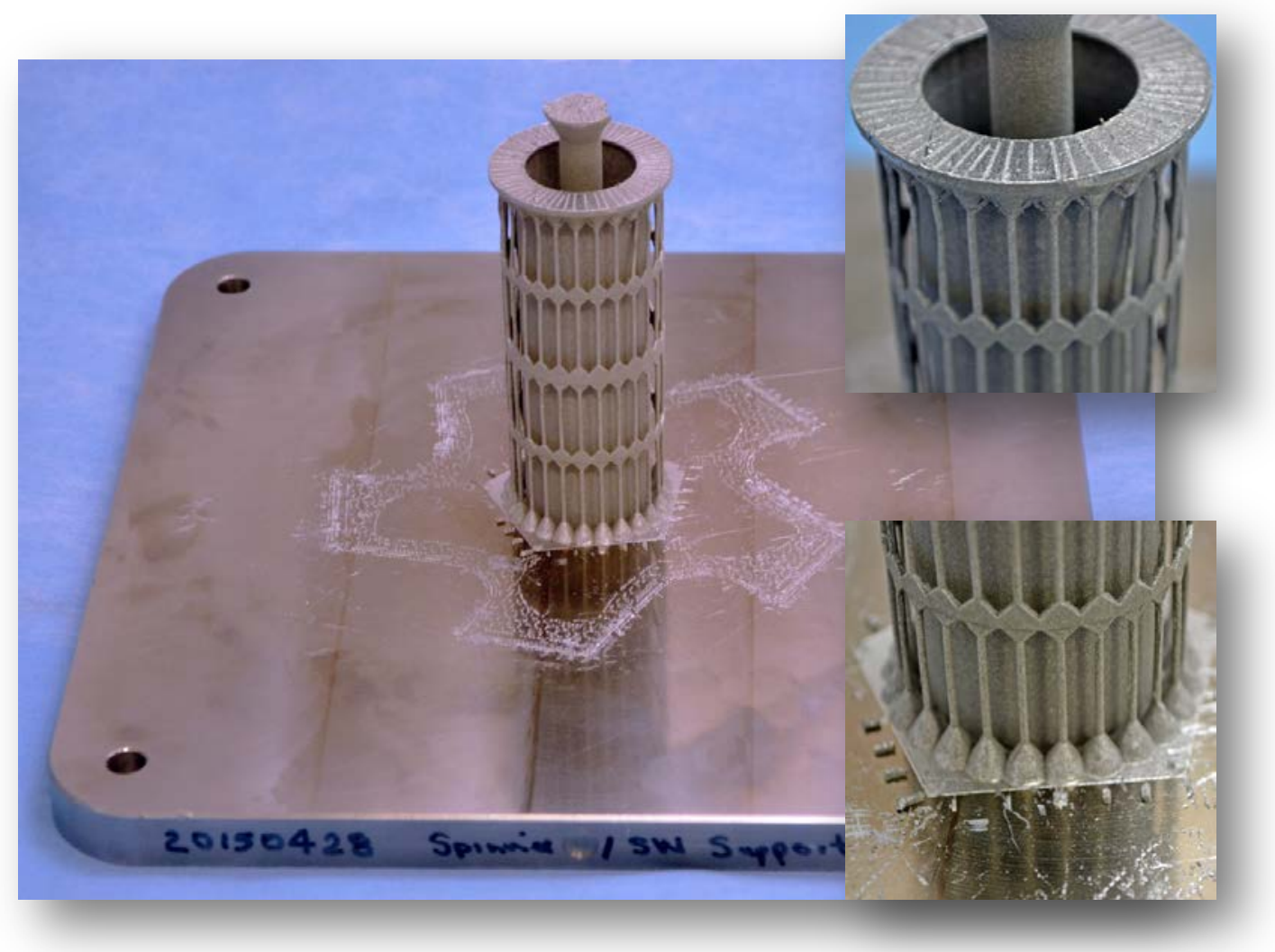

Fig, 4. Custom structure developed to thermally and mechanically support the mask fixture during building. 


\subsection{IMPACTS}

Additive manufacturing will have a substantial impact on the way EBPVD masking fixtures are produced in the future. The weight reduction of the fixtures will lead to productivity improvements because of the potential for increased heat up ramp rates. Space saving fixtures with high packing density will lead to productivity enhancements. Because of the fast turnaround the time to market for new product implementation (NPI) will be substantially shortened. This demonstration project has provided Praxair Surface Technologies with a direct understanding of the SLM process and its potential to fabricate complex masking fixtures from high temperature alloys. Additionally, the on-site exercise hosted by ORNL has facilitated the transfer of some of the important subtleties of the art of SLM that are difficult to capture in a document. Praxair Surface Technologies has moved forward with the purchase of a laser powder bed system in order to fabricate complex fixtures.

\subsection{CONCLUSIONS}

This project was successful in that it gave insight into the current deposition rates associated with both electron beam and laser based powder bed additive manufacturing technologies. It was determined that both EBM and laser powder bed had nearly identical deposition rates for a complex fixture utilized by Praxair Surface Technologies. However, because of the better surface finish and current state of the supply chain in the US for laser powder bed systems, it was determined this was the ideal processing method for this design. Therefore, PST has since purchased a laser powder bed system in order to continue efforts in additive manufacturing.

In addition, this work demonstrated that additional high temperature materials besides Inconel 718 could be fabricated using the laser powder bed process. Preliminary processing parameters such as laser power and scan speed were optimized. The resulting material was characterized and showed two different types of porosity; lack of fusion from not inputting enough energy and spherical porosity most likely associated from keyhole formation in laser welding or from porosity already inherent in the starting feedstock. However, cracking was not observed in this material. The quantity and size of defects in the material were low enough that PST determined this material would be suitable for their application, as this is a non-structural application.

\section{PARTNER BACKGROUND}

Praxair Surface Technologies consists of 2,500 engineers, technologists and coating experts across more than 35 sites in 12 countries. Praxair Surface Technologies works to create surface-enhancing materials while utilizing innovative processes, equipment and technology. PST focuses on advanced coatings that extend the life of critical components and keep various businesses running as efficiently and productively as possible. Praxair Surface Technologies is a leading global supplier of surface-enhancing processes and materials as well as an innovator in thermal spray, composite electroplating, diffusion, and highperformance slurry coatings processes. PST produces and applies metallic and ceramic coatings that protect critical metal components from a variety of environmental conditions, including wear, corrosion, and high temperatures.

The company is a subsidiary of Praxair Inc., one of the largest industrial gases companies in the world and the largest in North and South America. Praxair is a Fortune 300 company with 2010 sales of \$10.1 billion. 